\title{
Familial scaphocephaly syndrome caused by a novel mutation in the FGFR2 tyrosine kinase domain
}

\author{
G McGillivray, R Savarirayan, T C Cox, C Stojkoski, R McNeil, A Bankier, J F Bateman, T Roscioli, \\ R J M Gardner, S R Lamandé
}

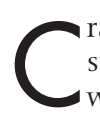
raniosynostosis, the premature fusion of one or more sutures of the skull, is a common craniofacial anomaly, with an estimated incidence of $1 / 2000$ to $1 / 3000$ births. ${ }^{12}$ Characteristic deformities of skull shape occur as a result of different patterns of sutural fusion, while compensatory skull expansion occurs at unaffected sutures to accommodate the growing brain. Premature fusion of the sagittal suture, for example, results in anterior to posterior elongation of the skull known as scaphocephaly. ${ }^{2}$ Sagittal synostosis is the most common type of craniosynostosis, occurring in $40-58 \%$ of cases reported in large neurosurgical surveys, and shows a male predominance. ${ }^{3-6}$ Most of the cases in these reports are "non-syndromic" instances of sagittal synostosis, while familial cases represent $2-9 \%$ of the total. Mental retardation is uncommon in isolated sagittal synostosis, but is more common in cases with associated malformations. ${ }^{4-6}$ Over 90 syndromic forms of craniosynostosis have been described. Apert, Crouzon, Pfeiffer, Muenke, and Saethre-Chotzen syndromes are the most common of these, being classified according to the clinical involvement of the cranium, face, hands and feet, and other organs. ${ }^{2}$ In these syndromes, brachycephaly or acrocephaly resulting from coronal synostosis is the predominant cranial deformity, and this is variably associated with mid-face hypoplasia, broad toes, syndactyly, and intellectual deficits. Sagittal synostosis is seen almost exclusively in combination with coronal synostosis, ${ }^{2}$ while macrocephaly in the absence of craniosynostosis occurs infrequently. ${ }^{7}$ Familial scaphocephaly syndromes, which include Berant syndrome, "Philadelphia" type craniosynostosis, and Jones craniosynostosis, ${ }^{2}$ are rare and their molecular aetiology remains unknown.

Mutations in five genes have been shown to cause various craniosynostosis syndromes. These are the transcription factor genes TWIST (Saethre-Chotzen syndrome, MIM 101400) and MSX2 (Boston-type craniosynostosis, MIM 604757), and three fibroblast growth factor receptor genes, FGFR1, FGFR2, and FGFR3 (Pfeiffer syndrome, MIM 101600; Apert syndrome MIM 101200; Crouzon syndrome, MIM 123500; Jackson-Weiss syndrome, MIM 123500). ${ }^{1}$ Mutations in TWIST, FGFR2, and FGFR3 also cause isolated nonsyndromic coronal synostosis ${ }^{8}$; however, mutations resulting in isolated sagittal suture synostosis and scaphocephaly have yet to be identified. The FGFR mutations have been located predominantly in hotspots in these genes in the more than 800 patients where mutations have been characterised. ${ }^{19}$ Only one FGFR1 mutation, P252R, has been identified and it results in a mild Pfeiffer syndrome variant. ${ }^{10}$ In contrast, FGFR2 mutations are a common cause of several craniosynostosis syndromes: Pfeiffer, Apert, Crouzon, Jackson-Weiss, and Beare-Stevenson (MIM 123790). ${ }^{11}$ The FGFR2 mutations are non-randomly distributed throughout the gene, concentrated in exons 8 and 10. Two mutations, S252W and P253R, are relatively common and invariably cause Apert syndrome. ${ }^{11}$ In FGFR3, the A391E mutation causes Crouzon

\section{Key points}

- A large family is reported in which three generations show dominant inheritance of a new craniosynostosis syndrome characterised by scaphocephaly, macrocephaly, severe maxillary retrusion, and mild intellectual disability.

- Molecular analysis revealed a novel K526E mutation in the TK1 portion of the intracellular split tyrosine kinase domain of the fibroblast growth factor receptor 2 gene (FGFR2). The mutation is located at the cleft between the TK1 and TK2 lobes of the domain and is predicted to stabilise the activation loop in an active conformation.

- This is the first report of a mutation causing a familial scaphocephaly syndrome with almost exclusive involvement of the sagittal suture. These data indicate that FGFR2 mutations are responsible for an extended range of phenotypes, which might include isolated sagittal synostosis; they underline the importance of extending FGFR2 mutation screening beyond the known mutation hotspots.

syndrome with acanthosis nigricans and the P250R mutation causes Muenke syndrome (MIM 602849). Mutations in FGFR3 also cause thanatophoric dysplasia (MIM 187600). Although craniosynostosis is a feature of this disorder, it is more commonly considered a severe generalised skeletal dysplasia. ${ }^{11}{ }^{12} F G F R 3$ mutations also result in a range of other chondrodysplasias including achrondroplasia and hypochondroplasia, emphasising the central role that FGF signalling plays in skeletal development. ${ }^{12}$ The wide range of limb abnormalities that occurs in the craniosynostosis syndromes indicates that the pathways of cranial bone growth and limb morphogenesis share some critical components. Characterisation of the genes involved in these syndromes is providing important information about the regulatory pathways of craniofacial and skeletal development.

We report the clinical and molecular findings in a three generation family showing autosomal dominant inheritance of a novel craniosynostosis syndrome (fig 1). Thirty family members were examined and the clinical findings are detailed in table 1 . The appearances of the 11 affected individuals are shown in fig 2 . The study was approved by the Royal Children's Hospital ethics in human research committee, and informed consent was obtained from participating family members. All the subjects shown in fig 2, or their legal guardians, gave written consent for their images to be reproduced in this paper. Macrocephaly was defined as an occipito-frontal circumference greater than the 98th centile 


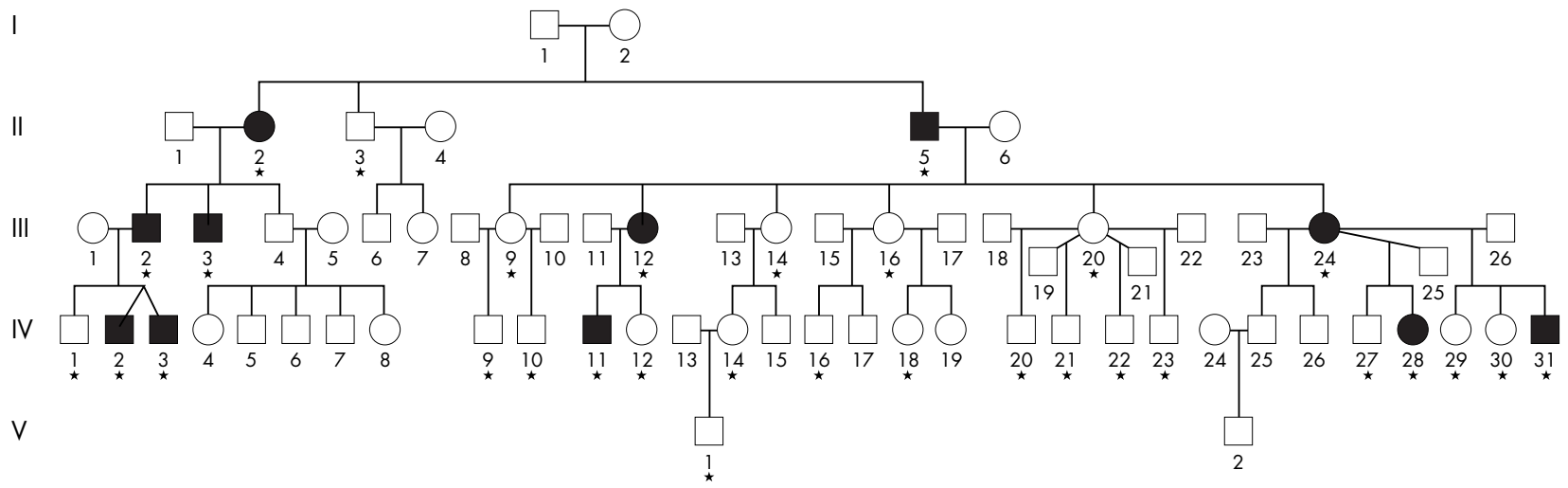

* Individuals who underwent detailed clinical examination

Figure 1 Pedigree of the family affected with a novel scaphocephaly syndrome.

for age. ${ }^{13}$ Hypertelorism was defined as an interpupillary distance greater than the 97th centile for age. ${ }^{14}$ Intellectual disability was determined by formal neuropsychological testing in individual IV:11 (Wechsler intelligence scale for children), and by paediatric assessment of individuals IV:2 and IV:31. Individual III:3 did not succeed at mainstream schooling and at 36 years of age was unable to live independently. He was thus considered to have an intellectual disability. Learning difficulty in other individuals was based on family reporting of schooling difficulties. Statistical analysis of the relation between genotype and learning difficulties was carried out using Pearson's $\chi^{2}$ test.

The 11 affected individuals have varying degrees of craniofacial dysmorphism (fig 1, table 1). Seven (63\%) have scaphocephaly and 10 (91\%) have macrocephaly. Of 19 unaffected individuals, three had macrocephaly with tall stature, and none had scaphocephaly. More severely affected individuals (for example, IV:11 and III:3) are male and have scaphocephaly, macrocephaly, a high forehead, marked midface hypoplasia with severe maxillary retrusion, relative or absolute prognathism, and class III malocclusion. This results in a "scooped out" or concave profile. More severely affected individuals have intellectual disability in the borderline to mild range.

Proband IV:11 presented aged four years with scaphocephaly, macrocephaly, and severe maxillary retrusion, and he has "borderline" intellectual ability (WISC-III). Sagittal synostosis was confirmed radiologically. He had surgery at 10 and 15 years of age (Le Forte III and maxillary distraction osteotomy, respectively) to advance his midface, improve his dental occlusion, and for cosmetic reasons.

The only other family member who underwent craniofacial surgery was individual IV:31. He had congenital trigonocephaly from metopic synostosis, congenital macrocephaly with macrosomia, broad and medially deviated great toes, complete soft tissue syndactyly of the second and third toes, mild "dysplastic" cerebral ventriculomegaly, and mild developmental delay. He had a bilateral surgical frontoorbital advancement to correct the metopic synostosis at eight months for cosmetic reasons. His mother (III:24) has a broad great toe and partial 2,3 syndactyly of the toes. Radiographs of the feet of IV:31 and III:24 confirmed the clinical findings, but did not show bony fusion.

Aside from IV:31 and III:24, none of the family members had significant feet findings on examination, and none had hand abnormalities. Mildly affected individuals (for example, II:2) have macrocephaly with a high forehead and mild maxillary retrusion. Hypertelorism appeared to be proportional to the macrocephaly. Affected individuals have variable stature ranging from the 3rd to above than the 97th centile for age.

The clinical presentation of this family thus appears distinct from other known craniosynostosis syndromes. Sagittal synostosis in the absence of coronal synostosis has

Table 1 Summary of clinical findings in 11 affected family members

\begin{tabular}{|c|c|c|c|c|c|c|c|c|c|c|c|}
\hline Characteristic & II:2 & II:5 & III:2 & III:3 & III:12 & III:24 & IV:2 & IV:3 & IV:11 & IV:28 & IV:31 \\
\hline Scaphocephaly & - & + & - & + & - & + & + & + & + & + & $-^{*}$ \\
\hline Macrocephaly & + & + & + & + & + & + & - & + & + & + & + \\
\hline Head circumference $†$ & 58.5 & 63.5 & 61 & 63 & 59 & 58 & 56 & 57.8 & 59 & 60 & 55.5 \\
\hline 98th centile & 57.6 & 58.2 & 58.2 & 58.2 & 57.6 & 57.6 & 57.2 & 57.2 & 57.8 & 56.2 & 52.5 \\
\hline High forehead & + & - & + & - & + & + & + & + & + & + & + \\
\hline Hypertelorism $\ddagger$ & - & + & + & + & + & + & + & + & + & + & + \\
\hline Maxillary retrusion & + & + & + & + & + & + & + & + & + & + & + \\
\hline Malocclusion & - & + & - & + & + & - & - & + & + & + & + \\
\hline Prognathism§ & - & - & + & + & + & - & - & - & - & - & - \\
\hline High arched palate & + & - & + & - & + & - & + & + & + & - & + \\
\hline Syndactyly & - & - & - & - & - & + & - & - & - & + & ++ \\
\hline Broad great toe & - & - & - & - & - & + & - & - & - & - & + \\
\hline Learning difficulty** & - & + & + & ++ & - & - & ++ & + & H & + & ++ \\
\hline
\end{tabular}

*Trigonocephaly.

†Head circumference in $\mathrm{cm}$; standard head circumference and percentile values are those described in reference 13.

†Proportional to macrocephaly.

$\S$ Absolute prognathism.

$\checkmark 2,3$ Soft tissue toe syndactyly; +, partial; ++, complete.

$*^{*}+$, family reporting schooling difficulties; ++ , borderline or mild intellectual disability or developmental delay on clinical assessment (see text).

ND, not determined; +, present; -, absent. 

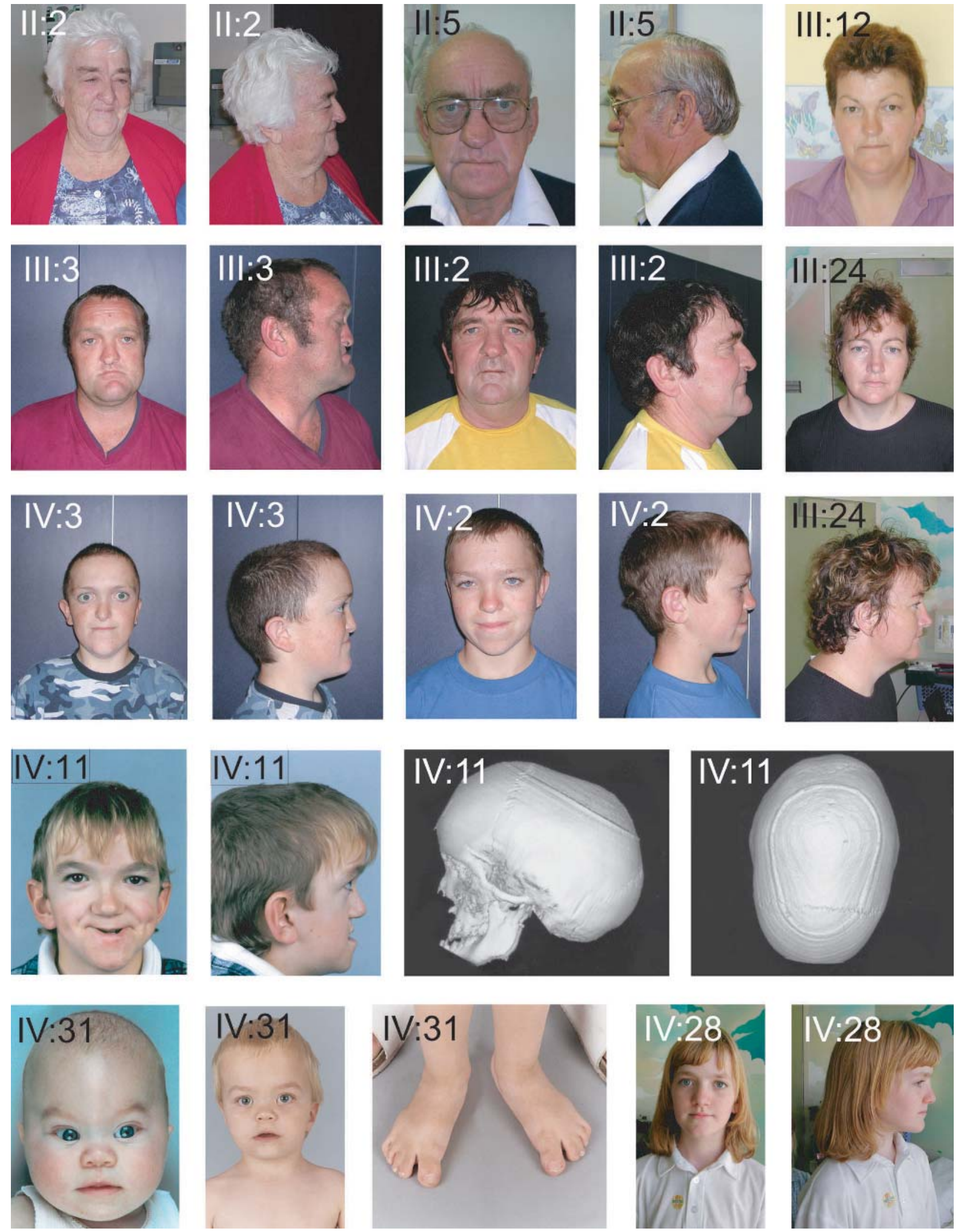

Figure 2 Appearances of affected family members. Photographs of the 11 affected family members are shown. Lateral photographs of individuals IV:1 1, II:5 and III:3 show the "scooped out" profile resulting from the severe maxillary retrusion. The three dimensional craniofacial computed tomography scans of individual IV:11 show the patent coronal and lamboid sutures, and the complete obliteration of the sagittal suture. Individual IV:31 is shown before and after craniofacial surgery and the photograph of his feet illustrates the complete 2,3 soft tissue toe syndactyly and the broad great toe. Written consent was obtained from patients or legal guardians for publication of these clinical photographs. 
A
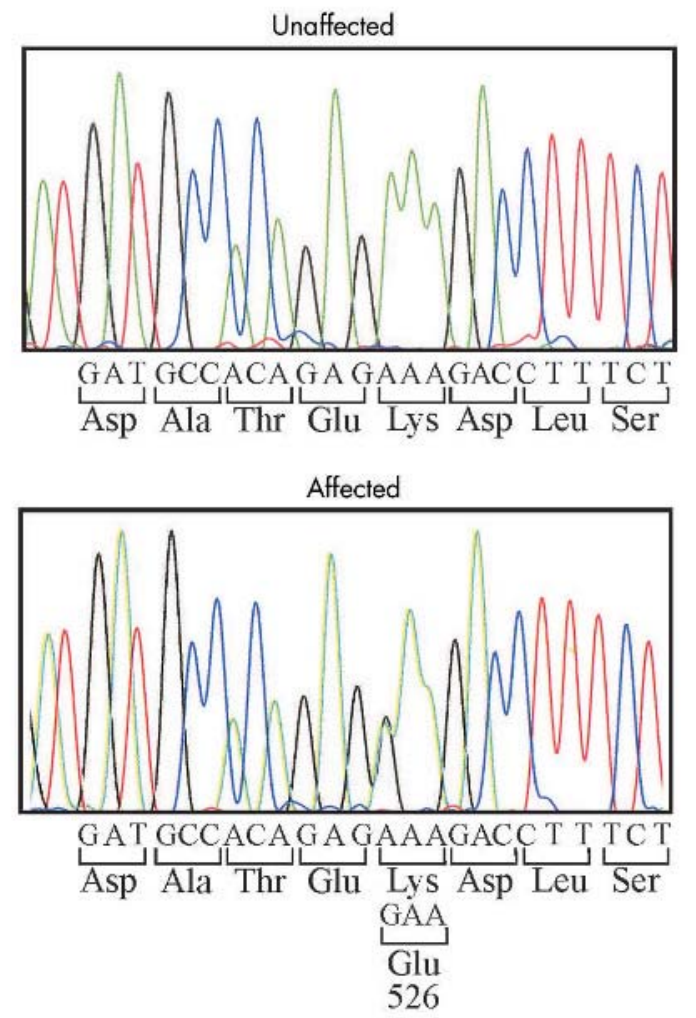

B

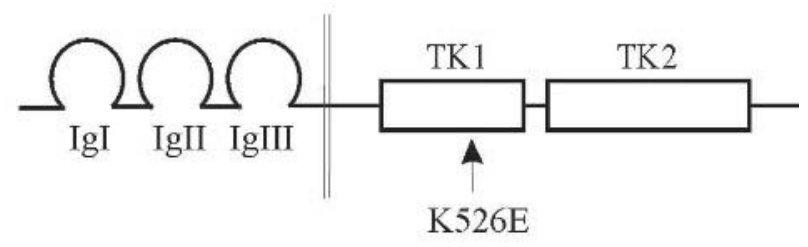

C

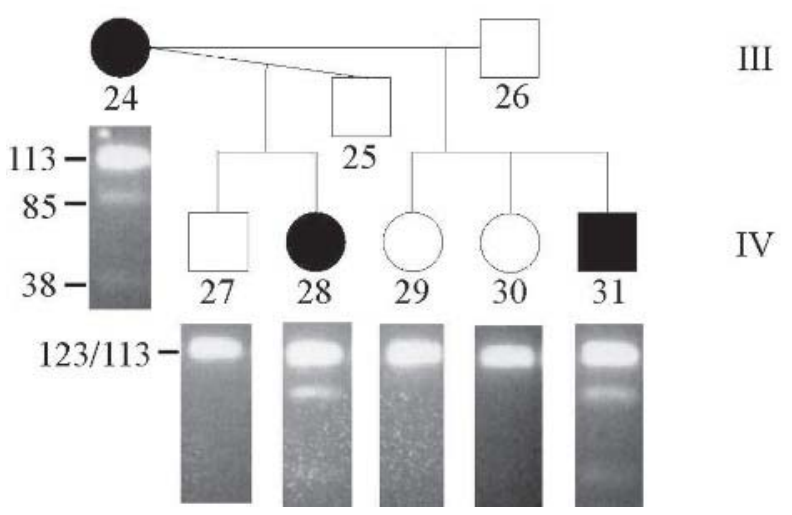

Figure 3 A mutation in the FGFR2 tyrosine kinase domain. (A) A heterozygous $A \rightarrow G$ substitution in FGFR2 exon 14 that resulted in a K526E amino acid substitution was identified in affected family members (lower chromatogram). Protein translations of the first eight complete codons of exon 14 are shown below the chromatogram. This mutation was not present in unaffected family members or controls (upper chromatogram). (B) The novel K526E mutation (arrow) is in the TK1 portion of the split tyrosine kinase domain. The FGFR2 extracellular immunoglobulin-like domains, Igl, Igll, and Iglll are shown, and the cell membrane is indicated by the two vertical lines. The intracellular split been reported in Crouzon syndrome in a small percentage of cases, and usually in combination with lambdoid synostosis. ${ }^{2}$ The absence of shallow orbits and ocular proptosis in members of this kindred excludes Crouzon syndrome. Similarly, Pfeiffer syndrome is distinguished by the presence of broad thumbs, and this feature was not present in any affected family members.

A significant proportion of affected individuals had a history of learning difficulties when compared with unaffected family members $\left(\chi^{2}=9.7, p=0.002\right)$. This difference remained significant after exclusion of the propositi. Mild intellectual disability was associated with a more severe craniofacial phenotype in III:3, IV:2, IV:11, and IV:31. The absence of intracranial hypertension in scaphocephalic family members and the associated facial malformation indicates that intellectual impairment might be a primary consequence of the gene mutation rather than a secondary effect related to timing of surgery.

Initially, we screened for mutations in the genes known to be associated with craniosynostosis. The FGFRI P252R mutation found in mild Pfeiffer syndrome, and the Muenke syndrome FGFR3 P250R mutation ${ }^{1}$ were not detected in patient IV:11 by diagnostic restriction enzyme digestion of genomic polymerase chain reaction (PCR) products. The FGFR2 mutation hot spots in exons 8, 10, and 11 identified in Apert, Crouzon, Pfeiffer, and Beare-Stevenson syndromes, ${ }^{1}{ }^{9}$ and the single coding exon of TWIST which contains mutations in Saethre-Chotzen syndrome patients, ${ }^{1}$ were screened by denaturing high performance liquid chromatography (DHPLC) and gene sequencing. No mutations were found. An activating mutation in the homeobox gene MSX2 causes dominantly inherited Boston-type craniosynostosis ${ }^{15}$ and so we directly sequenced the two exons of $M S X 2$. We also sequenced the $A L X 4$ gene, haploinsufficiency of which results in parietal foramina. ${ }^{16}$ No mutations were found in either of these genes.

While most of the characterised FGFR2 mutations are located in exons 8 and 10 which code for the third extracellular immunoglobulin-like domain (IgIII), or in exon 11 which encodes the transmembrane domain, a recent complete FGFR2 mutation screen identified mutations in six additional exons-3, 5, 14, 15, 16, and 17.' We therefore screened these exons by DHPLC of genomic PCR products and direct sequencing.

A heterozygous base change, c. 1576A $\rightarrow \mathrm{G}$, was identified in exon 14 of FGFR2 in patient IV:11 (fig 3A). This is a novel change that results in a non-conservative amino acid substitution, K526E, within the intracellular TKl domain (fig 3B). The base change creates a new MboII restriction enzyme recognition site that allowed the development of a diagnostic restriction enzyme assay to track the change in affected and unaffected family members and controls (fig 3C). The change was found in all 11 affected individuals but not in the 19 unaffected family members who were examined, nor in 110 control chromosomes (data not shown), indicating that FGFR2 K526E is not a common polymorphism and is likely to be the pathogenic mutation in this family. Consistent with this, a lysine residue is found in

tyrosine kinase domain (TK1 and TK2) is indicated by the two boxes. (C) The presence of the mutation was tracked by restriction enzyme digestion (Mboll) of genomic polymerase chain reaction products from 30 family members. The analysis of six family members is shown. Wild-type genotypes resulted in fragments of 123,113, and 13 bp (individuals IV:27, IV:29, and IV:30). The 123 and 113 bp bands were not resolved and the $13 \mathrm{bp}$ band is too small to see. Carriers of the mutation have bands of $113,85,38$, and 13 bp (individuals III:24, IV:28, and IV:31). Eleven affected individuals carried the mutation and it was not present in 19 unaffected family members or in 110 control chromosomes. 
A

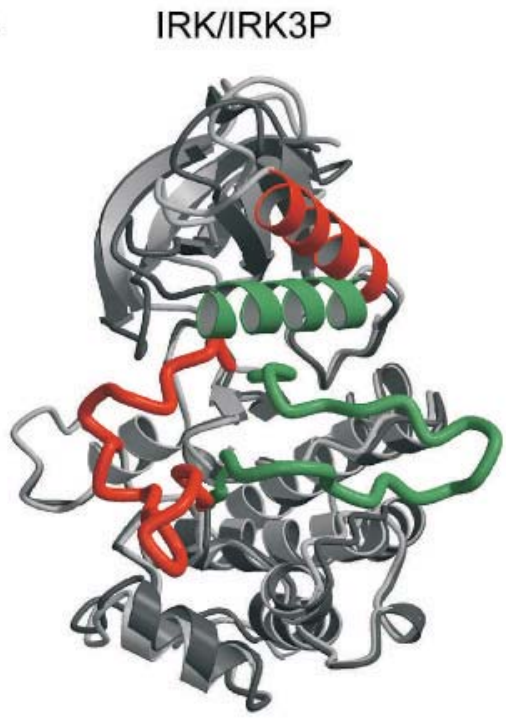

FGFR2 K526/FGFR2 E526

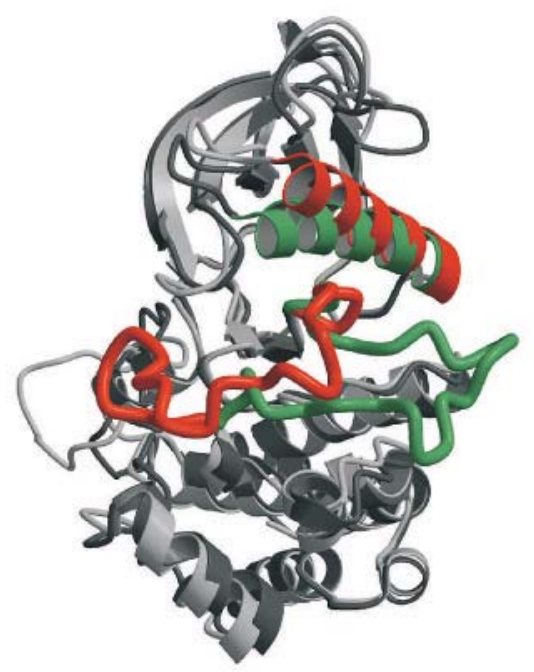

FGFR2 E526

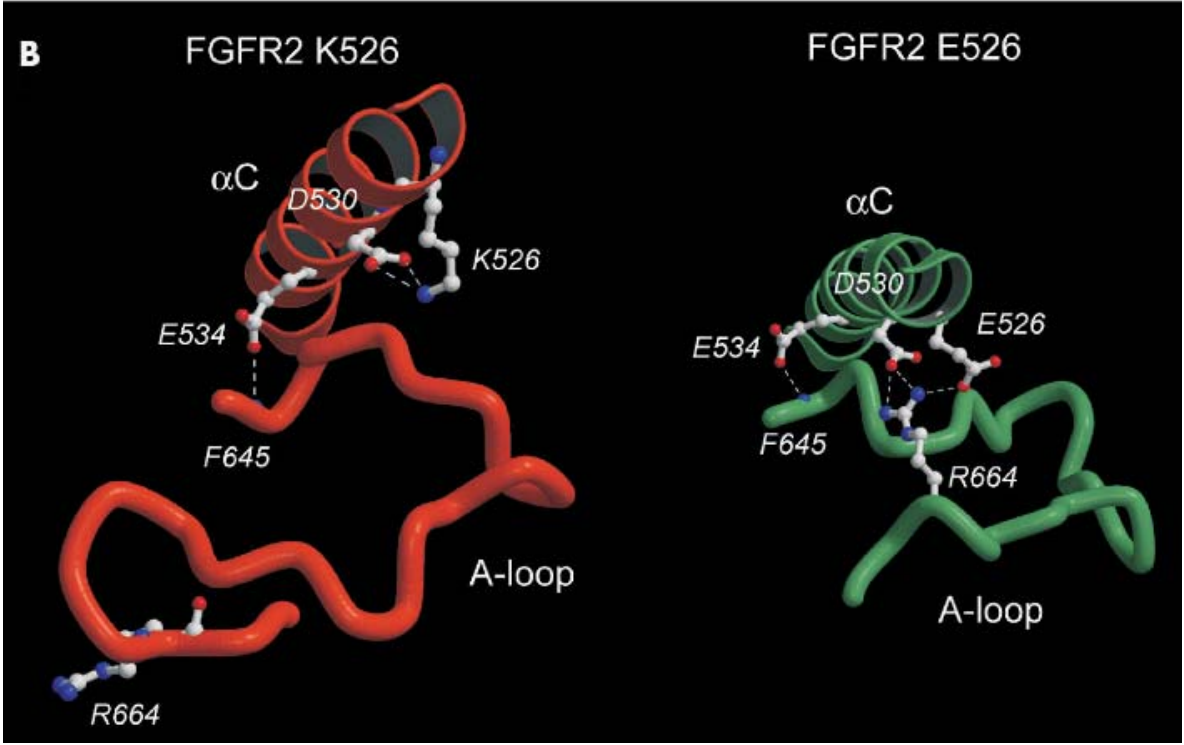

Figure 4 Comparison of the insulin receptor and FGFR2 tyrosine kinase domains. (A) Superimposition of the ribbon diagrams of the insulin receptor tyrosine kinase domain (IRK) coloured light grey, and the activated form of the insulin receptor tyrosine kinase (IRK3P) coloured dark grey, is shown on the left. The $\alpha \mathrm{C}$ helix and the activation loop (A loop) of IRK is shown in red and the $\alpha \mathrm{C}$ helix and A loop of IRK3P is shown in green. Superimposition of the homology model of the wild-type FGFR2 tyrosine kinase domain (FGFR2 K526, light grey) and the K526E mutant tyrosine kinase (FGFR2 E526, dark grey) is shown on the right. The $\alpha \mathrm{C}$ helix and the activation loop (A loop) of the wild-type tyrosine kinase, K526, is shown in red and the $\alpha \mathrm{C}$ helix and A loop of the mutant, E526, is shown in green. The conformation of the A loop of the mutant E526 tyrosine kinase resembles the active state seen in IRK3P. (B) The $\alpha$ C helix and activation loop of the inactive wild-type FGFR2 (left) and mutant FGFR2 E526 tyrosine kinase (right). The representations are taken from the superimposed ribbon diagram in $(\mathrm{A})$ and equivalently rotated to more clearly show key interacting residues from the $\alpha \mathrm{C}$ helix and A loop. In the wild-type, K526 forms a salt bridge with D530; however, in the mutant the substituted E526 residue and D530 both interact with R664, thereby stabilising the A loop of FGFR2 in an active conformation. The carbon atoms of these residues are indicated in white, oxygen atoms in red, and nitrogen atoms in blue. The hydrogen bond between E534 and the backbone amide hydrogen of F645 is the only other example of bonding between the $\alpha \mathrm{C}$ helix and the activation loop. Hydrogens are not shown. The figures were prepared with MOLSCRIPT. ${ }^{22}$

the 526 position, or its equivalent, in all FGFR proteins, suggesting that it plays a crucial role in FGFR tyrosine kinase domain function. This is the first report of a pathogenic mutation in a craniosynostosis syndrome manifesting predominantly as scaphocephaly.

To assess the potential pathogenic significance of the mutation we produced structural models of the wild-type (K526) and mutant E526 FGFR2 tyrosine kinase domain (fig 4). The models were based on coordinates from the publicly available crystal structures of the FGFRI ${ }^{17}$ (PDB IFGI) and FGFR2 (PDB IGJO) tyrosine kinase domains. The models were produced using the program MODELLER, and refined by conjugate gradient energy minimisation and simulated annealing in explicit water using the program NAMD. ${ }^{18-20}$ All modelling was carried out on the supercomputing facilities at the South Australian Partnership for Advanced Computing (Adelaide, South Australia). Structural comparison with the published structures of the kinase domains from FGFRl, ${ }^{17}$ insulin receptor (IRK), and the activated insulin receptor (IRK3P) ${ }^{21}$ confirms that K526 of the wild-type FGFR2 is located in the $\alpha \mathrm{C}$ helix at the interface between the $\mathrm{N}$-terminal ATP binding lobe and the C-terminal 
substrate binding/catalytic lobe and forms a salt bridge with the adjacent aspartate residue at position 530 (fig 4). Notably, in the model generated for the K526E mutant, the substituted E526 residue and D530 both interact with R664, thereby stabilising the activation loop (A loop) of FGFR2 in an active conformation (fig. 4). Activation of tyrosine kinase domains is accomplished by the ligand dependent autophosphorylation of tyrosine residues in the A loop. This phosphorylation results in a dramatic conformational change in the A loop that permits the binding of ATP and substrate peptide (fig 4A). ${ }^{21}$ Our mutant model predicts that the E526 mutation results in stabilisation of the active conformation of the A loop of the FGFR2 tyrosine kinase domain that probably occurs in the absence of activating ligand. This predicted ligand independent activation will require experimental confirmation.

Six mutations have previously been identified in the intracellular tyrosine kinase domain of FGFR2. ${ }^{\circ}$ Like the K526E mutation described here, all these mutations were located in the cleft between the TK1 and TK2 domains and are thought to activate the tyrosine kinase domain. Two of the mutations $\mathrm{K} 659 \mathrm{~N}$ and $\mathrm{N} 549 \mathrm{H}$ are located at conserved residues equivalent to residues of FGFR 3 at which mutations have been experimentally shown to be activating. ${ }^{23}{ }^{24}$ The six previous FGFR2 tyrosine kinase domain mutations were identified in patients with syndromic craniosynostosis. Where phenotype data were present, all had either Crouzon syndrome or Pfeiffer syndrome. Some patients had broad thumbs and great toes, and developmental delay was overrepresented compared with typical Crouzon and Pfeiffer syndromes. ${ }^{9}$ One patient in this group, heterozygous for a K64lR mutation, had sagittal suture synostosis and scaphocephaly similar to the family described here, but also had broad thumbs with radial angulation and a facial appearance consistent with Pfeiffer syndrome. In contrast, two other Pfeiffer syndrome patients who also carried the K64lR mutation did not have scaphocephaly, emphasising the phenotypic variability that is common in craniosynostosis syndromes. There does not appear to be a set of clinical features that uniformly distinguishes patients with FGFR2 intracellular tyrosine kinase mutations from those with mutations in the extracellular region. The current study highlights the importance of extending FGFR mutation screening beyond the exon 8 and 10 hotspots. This is particularly important in patients and families with atypical craniosynostosis syndromes. The presence of mutations in the intracellular domains of FGFR2 should also be considered when sagittal synostosis is found in association with changes in midface development. The significance of FGFR2 mutations in isolated sagittal synostosis should be further assessed.

\section{ACKNOWLEDGEMENTS}

We thank the family for their willingness to be involved in this study. We wish to acknowledge and thank Professor M Michael Cohen Jr for offering his advice regarding this family on the occasion of a visit to Melbourne in 1993. We wish to acknowledge the contribution of Mr Anthony Holmes (Craniofacial Surgeon), Mr Andrew Heggie, (Craniofacial surgeon), and Ms Wirginia Maixner (Neurosurgeon) who were involved in the surgical care of two of the children. This work was supported by grants from the Murdoch Childrens Research Institute, the National Health and Medical Research Council of Australia, the Australian Craniofacial Unit, Adelaide, and a Keith Sheridan research associateship (to TCC) from the University of Adelaide.

\section{Authors' affiliations}

G McGillivray, R Savarirayan, A Bankier, R J M Gardner, Genetic

Health Services Victoria, Murdoch Childrens Research Institute, Royal Children's Hospital, Parkville, Australia
R Savarirayan, R McNeil, J F Bateman, S R Lamandé, Cell and Matrix Biology, Murdoch Childrens Research Institute

R Savarirayan, J F Bateman, S R Lamandé, Department of Paediatrics, University of Melbourne, Royal Children's Hospital, Parkville

T C Cox, C Stojkoski, School of Molecular and Biomedical Science, University of Adelaide, Australia

T C Cox*, Australian Craniofacial Institute, North Adelaide, Australia

A Bankier, Department of Paediatrics, Monash University, Clayton, Australia

T Roscioli, SEALS Molecular and Cyłogenetics Laboratory, Prince of Wales Hospital, Randwick, Australia

*Present affiliation: Department of Anatomy and Cell Biology, Monash University, Clayton, Australia

Competing interests: none declared

Correspondence to: Dr Shireen R Lamandé, Murdoch Childrens Research Institute, Royal Children's Hospital, Parkville 3052, Victoria, Australia; shireen.lamande@mcri.edu.au

Received 6 October 2004

Revised 13 December 2004

Accepted 21 December 2004

\section{REFERENCES}

1 Muenke M, Wilkie AO. Craniosynostosis syndromes. In: Beaudet AC, Kinzler K, Scriver $\mathrm{C}$, et al, eds. The metabolic and molecular bases of inherited disease. New York: McGraw-Hill, 2001:6117-46.

2 Cohen MM, MacLean RE. Craniosynostosis: diagnosis, evaluation, and management, 2nd ed. New York: Oxford University Press, 2000.

3 Anderson FM, Geiger L. Craniosynostosis: a survey of 204 cases. J Neurosurg 1965;22:229-40.

4 Hunter AG, Rudd NL. Craniosynostosis. I. Sagittal synostosis: its genetics and associated clinical findings in 214 patients who lacked involvement of the coronal suture(s). Teratology 1976;14:185-93.

5 Lajeunie E, Le Merrer M, Bonaiti-Pellie C, Marchac D, Renier D. Genetic study of scaphocephaly. Am J Med Genet 1996;62(3):282-5.

6 Shillito J, Matson DD. Craniosynostosis: a review of 519 surgical patients. Pediatrics 1968:41:829-53.

7 Muenke M, Gripp KW, McDonald-McGinn DM, Gaudenz K, Whitaker LA, Bartlett SP, Markowitz RI, Robin NH, Nwokoro N, Mulvihill JJ, Losken HW, Mulliken JB, Guttmacher AE, Wilroy RS, Clarke LA, Hollway G, Ades LC, Haan EA, Mulley JC, Cohen MM, Bellus GA, Francomano CA, Moloney DM, Wall SA, Wilkie AO, et al. A unique point mutation in the fibroblast growth factor receptor 3 gene (FGFR3) defines a new craniosynostosis syndrome. Am J Hum Genet 1997;60:555-64.

8 Mulliken JB, Gripp KW, Stolle CA, Steinberger D, Muller U. Molecular analysis of patients with synostotic frontal plagiocephaly (unilateral coronal synostosis). Plast Reconstr Surg 2004;113:1899.

9 Kan SH, Elanko N, Johnson D, Cornejo-Roldan L, Cook J, Reich EW, Tomkins S, Verloes A, Twigg SR, Rannan-Eliya S, McDonald-McGinn DM, Zackai EH, Wall SA, Muenke M, Wilkie AO. Genomic screening of fibroblast growth-factor receptor 2 reveals a wide spectrum of mutations in patients with syndromic craniosynostosis. Am J Hum Genet 2002;70:472-86.

10 Muenke M, Schell U, Hehr A, Robin NH, Losken HW, Schinzel A, Pulleyn U, Rutland P, Reardon W, Malcolm S, et al. A common mutation in the fibroblast growth factor receptor 1 gene in Pfeiffer syndrome. Nat Genet 1994;8:269-74.

11 Passos-Bueno MR, Wilcox WR, Jabs EW, Sertie AL, Alonso LG, Kitoh H. Clinical spectrum of fibroblast growth factor receptor mutations. Hum Mutat 1999;14:115-25.

12 Ornitz DM, Marie PJ. FGF signaling pathways in endochondral and intramembranous bone development and human genetic disease. Genes Dev 2002;16:1446-65.

13 Nellhaus G. Head circumference from birth to eighteen years. Practical composite international and interracial graphs. Pediatrics 1968;41:106-14.

14 Feingold M, Bossert WH. Normal values for selected physical parameters: an aid to syndrome delineation. Birth Defects Orig Artic Ser 1974:10:1-16.

15 Jabs EW, Muller U, Li X, Ma L, Luo W, Haworth IS, Klisak I, Sparkes R, Warman ML, Mulliken JB, ef al. A mutation in the homeodomain of the human MSX2 gene in a family affected with autosomal dominant craniosynostosis. Cell 1993;75:443-50.

16 Mavrogiannis LA, Antonopoulou I, Baxova A, Kutilek S, Kim CA, Sugayama SM, Salamanca A, Wall SA, Morriss-Kay GM, Wilkie AO. Haploinsufficiency of the human homeobox gene ALX4 causes skull ossification defects. Nat Genet $2001 ; 27: 17-8$.

17 Mohammadi M, Schlessinger J, Hubbard SR. Structure of the FGF receptor tyrosine kinase domain reveals a novel autoinhibitory mechanism. Cell 1996;86:577-87

18 Sali A, Blundell TL. Comparative protein modelling by satisfaction of spatial restraints. J Mol Biol 1993;234:779-815.

19 Linge JP, Williams MA, Spronk CA, Bonvin AM, Nilges M. Refinement of protein structures in explicit solvent. Proteins 2003;50:496-506. 
20 Kale L, Skeel R, Bhandarkar M, Brunner R, Gursoy A, Krawetz N, Phillips J, Shinozaki A, Varadarajan L, Schulten L. NAMD2: greater scalability for parallel molecular dynamics. J Comput Phys 1999:151:283-312.

21 Hubbard SR. Crystal structure of the activated insulin receptor tyrosine kinase in complex with peptide substrate and ATP analog. Embo J 1997; 16:5572-81

22 Kraulis PJ. MOLSCRIPT: a program to produce both detailed and schematic plots of protein structures. J Appl Crystallogr 1991;24:946-50.
23 Bellus GA, Spector EB, Speiser PW Weaver CA, Garber AT, Bryke CR Israel J, Rosengren SS, Webster MK, Donoghue DJ, Francomano CA. Distinct missense mutations of the FGFR3 lys 650 codon modulate receptor kinase activation and the severity of the skeletal dysplasia phenotype. Am J Hum Genet 2000;67:1411-21.

24 Raffioni S, Zhu YZ, Bradshaw RA, Thompson LM. Effect of transmembrane and kinase domain mutations on fibroblast growth factor receptor 3 chimera signaling in $\mathrm{PC} 12$ cells. A model for the control of receptor tyrosine kinase activation. J Biol Chem 1998:273:35250-9.

\section{Clinical Evidence-Call for contributors}

Clinical Evidence is a regularly updated evidence-based journal available worldwide both as a paper version and on the internet. Clinical Evidence needs to recruit a number of new contributors. Contributors are healthcare professionals or epidemiologists with experience in evidence-based medicine and the ability to write in a concise and structured way.

Areas for which we are currently seeking authors:

- Child health: nocturnal enuresis

- Eye disorders: bacterial conjunctivitis

- Male health: prostate cancer (metastatic)

- Women's health: pre-menstrual syndrome; pyelonephritis in non-pregnant women

However, we are always looking for others, so do not let this list discourage you.

Being a contributor involves:

- Selecting from a validated, screened search (performed by in-house Information Specialists) epidemiologically sound studies for inclusion.

- Documenting your decisions about which studies to include on an inclusion and exclusion form, which we keep on file.

- Writing the text to a highly structured template (about 1500-3000 words), using evidence from the final studies chosen, within 8-10 weeks of receiving the literature search.

- Working with Clinical Evidence editors to ensure that the final text meets epidemiological and style standards.

- Updating the text every six months using any new, sound evidence that becomes available. The Clinical Evidence in-house team will conduct the searches for contributors; your task is simply to filter out high quality studies and incorporate them in the existing text.

- To expand the topic to include a new question about once every 12-18 months.

If you would like to become a contributor for Clinical Evidence or require more information about what this involves please send your contact details and a copy of your CV, clearly stating the clinical area you are interested in, to Klara Brunnhuber (kbrunnhuber@ bmigroup.com).

\section{Call for peer reviewers}

Clinical Evidence also needs to recruit a number of new peer reviewers specifically with an interest in the clinical areas stated above, and also others related to general practice. Peer reviewers are healthcare professionals or epidemiologists with experience in evidence-based medicine. As a peer reviewer you would be asked for your views on the clinical relevance, validity, and accessibility of specific topics within the journal, and their usefulness to the intended audience (international generalists and healthcare professionals, possibly with limited statistical knowledge). Topics are usually 1500-3000 words in length and we would ask you to review between 2-5 topics per year. The peer review process takes place throughout the year, and our turnaround time for each review is ideally 10-14 days.

If you are interested in becoming a peer reviewer for Clinical Evidence, please complete the peer review questionnaire at www.clinicalevidence.com or contact Klara Brunnhuber (kbrunnhuber@bmigroup.com). 